\title{
Asambleas socioambientales en el devenir público-político de las controversias sociotécnicas en relación al agronegocio
}

\author{
Socio-environmental assemblies in the public-political future of socio-technical controversies in relation to \\ agribusiness
}

Nicolás Forlani

Centro de Estudios Avanzados / Universidad Nacional de Córdoba - CONICET, Argentina

forlani.nicolas@gmail.com

\begin{abstract}
Resumen:
El praxis de los espacios asamblearios socioambientales en su incidencia respecto a las controversias sociotécnicas, es decir diferencias al interior de la tecnociencia y/o entre objetivo del presente trabajo es abordar la esta y otros actores sociales, que han acontecido en las universidades públicas en torno a la expansión de la lógica hegemónica de producción agrícola en Argentina (agronegocio). Más precisamente la investigación se centra en un estudio de caso que revisa las acciones colectivas de las Asambleas Malvinas Lucha Por La Vida (Malvinas Argentinas) y Río Cuarto Sin Agrotóxicos (Río Cuarto) en relación a su antagonismo frente a los centros de experimentación de transgénicos que Monsanto pretendía construir y poner en funcionamiento en la provincia de Córdoba, abordando el lugar que en sus estrategias y repertorios ocuparon las Universidades Nacionales de Córdoba y Río Cuarto. El enfoque metodológico bajo el que cual se desarrolló la presente pesquisa fue de carácter cualitativo descriptivo, para el que recurrimos a diversas técnicas de recopilación de datos, tales como: observación participante, entrevistas semi-estructuradas, recopilación e interpretación de documentos oficiales emitidos por las Asambleas así como los producidos por las universidades y las publicaciones de la prensa. Lo anunciado anticipa la utilización de fuentes primarias y secundarias.
\end{abstract}

Palabras ClaVe: Controversias sociotécnicas, Universidades, Asambleas Socioambientales, Agronegocio.

\begin{abstract}
Aвstract:
The objective of this paper is to address the praxis of socio-environmental assembly spaces in their incidence with respect to sociotechnical controversies, that is, differences within technoscience and / or between this and other social actors, which have occurred in public universities around to the expansion of the hegemonic logic of agricultural production in Argentina (agribusiness). More precisely, the research focuses on a case study that reviews the collective actions of the Malvinas Assemblies Fight for Life (Malvinas Argentinas) and Río Cuarto Without Agrotoxics (Río Cuarto) in relation to their antagonism against transgenic experimentation centers that Monsanto intended to build and put into operation in the province of Córdoba, addressing the place that the National Universities of Córdoba and Río Cuarto occupied in their strategies and repertoires. The methodological approach under which the present investigation was developed was of a descriptive qualitative nature, for which we resorted to various data collection techniques, such as: participant observation, semi-structured interviews, compilation and interpretation of official documents issued by the Assemblies as well as those produced by universities and press publications. The announcement anticipates the use of primary and secondary sources.
\end{abstract}

KEYWORDS: Sociotechnical controversies, Universities, Social-environmental assemblies, Agribusiness.

\section{INTRODUCCIÓN:}

El advenimiento del agronegocio como lógica agrícola predominante en la Argentina contemporánea ha significado más que la adopción de un cultivo o agroquímico en particular. Pues el devenir del agro como negocio (sentido estricto Gras y Hernández, 2013) implicó el despliegue de una auténtica construcción hegemónica que asignó roles, jerarquías e incluso implicó notables transformaciones socioespaciales (como la co-dependencia entre lo urbano y lo rural) en tanto clave para la expansión de un modelo agrícola en el que los recursos financieros, científicos, informacionales y comunicacionales ocupan lugares centrales.

Recepción: 04 de marzo de 2019 | Aprobación: 08 de abril de 2019 | Publicación: 24 de octubre de 2019

Cita sugerida: Forlani, N. (2019). Asambleas socioambientales en el devenir público-político de las controversias sociotécnicas en relación al agronegocio. Cuestiones de Sociología, 20, e086. https://doi.org/10.24215/23468904e086 
Sin embargo, a pesar de la activa construcción de legitimidad que acompañó esta lógica productiva -en la que intervinieron dispositivos como la responsabilidad social empresarial, cursos y seminarios de formación agrícola, co-financiamiento privado-estatal para investigaciones sobre tecnologías del sector, publicidad en medios y redes de comunicación, etc.- la universalización de su particularidad no significó empero la clausura del disenso. Es que adscribiendo a perspectivas sociológicas del conflicto y, en particular, mediante una interpretación de la constitución de lo social y el despliegue de lo político desde la teoría de la hegemonía de autores como Ernesto Laclau y Chantal Mouffe (1985), entendemos que todo orden hegemónico y dentro de él, por caso el del agronegocio, finalmente no deja de ser contingente, es decir, que remite a particulares conformaciones sociopolíticas bajo coordenadas tempo/espaciales pasibles de ser cuestionadas y dislocadas.

Ahora bien en lo que atañe a la constitución del orden sociohistórico en torno a la agricultura industrial, es factible reconocer que el conocimiento científico -y las universidades como espacios públicos legitimados "como casas de altos estudios" en particular- jugó un rol crucial en el aval y desarrollo del paquete tecnológico del agro moderno (transgénicos, agroquímicos, siembra directa). Sin embargo el carácter fallido y contingente de este y cualquier orden social es lo que abre la posibilidad para que discursos críticos (parciales o radicales) irrumpan en la escena pública cuestionando las matrices o pilares en los que se funda la lógica productiva y societal referida. Precisamente allí han de inscribirse las controversias socio técnicas que abordamos en el presente trabajo, es decir los desacuerdos que tuvieron lugar en las Universidades Nacionales de Córdoba y Río Cuarto (Córdoba / Argentina) en relación a las plantas/laboratorios experimentales de transgénicos que la multinacional Monsanto pretendía instalar en las localidades de Malvinas Argentinas y Río Cuarto ${ }^{1}$.

Tal como lo analizaremos con posterioridad, tales controversias no pueden ser estudiadas ni comprendidas en ausencia de una conflictividad social que tuvo a los discursos (prácticas, acciones y saberes) de las asambleas socioambientales como protagonistas. Antes de analizar dicha conflictividad y detenernos en su injerencia en el desenlace de las controversias al interior de la academia consideramos pertinente precisar, al menos en una profundidad acorde a las pretensiones de esta investigación de carácter cualitativa descriptiva, el sentido que le adjudicamos a ciertos conceptos y categorías teóricas/analíticas así como lo referido al diseño metodológico que guía la presente pesquisa.

\section{CONSIDERACIONES TEÓRICO METODOLÓGICAS PRELIMINARES}

Antes de abordar la praxis de los movimientos socioambientales Malvinas Lucha Por La Vida (Malvinas Argentinas) y Río Cuarto Sin Agrotóxicos (Río Cuarto) en relación a su incidencia en los posicionamientos que las dos universidades públicas nacionales de la provincia (Universidad Nacional de Río Cuarto Universidad Nacional de Córdoba) expresaron en relación a las pretensiones de la multinacional del agronegocio Monsanto de construir centros experimentales de transgénicos; consideramos pertinente (según lo ya anunciado) explicitar el sentido que adjudicaremos a conceptos y/o nociones transversales al tema/ problema del presente escrito. Entre otros los referidos a: acción colectiva, protesta social, movimientos sociales / socioambientales; agronegocio; Estado y universidades públicas; controversias socio técnicas; ciencia y poder.

La acción colectiva y el estudio de los movimientos sociales ha sido objeto de prolíficos debates y amplias producciones teóricas e investigaciones empíricas. No es la intención aquí describir las distintas tradiciones que disputaron la interpretación en lo que refiere al accionar colectivo y la constitución de movimientos sociales, en rigor ya existen también abundantes estudios cuyo objeto apuntan precisamente a una sistematización de las distintas escuelas dedicadas a tal asunto ${ }^{2}$. Tampoco tenemos el objetivo aquí de precisar todas y cada una de las críticas de los que son pasibles los enfoques o tradiciones que se disputaron promediando la segunda mitad del siglo XX los estudios sobre los movimientos sociales. Sin embargo nos remitiremos a dos debilidades a partir de las cuales concebimos necesaria la incorporación de reflexiones de 
pensadores contemporáneos a los efectos de disponer de herramientas analíticas para describir y comprender la conflictividades y disputas que pretendemos abordar.

La tradición norteamericana, aun en su pluralidad de vertientes, en tanto tributaria o influenciada por el modelo economicista de Olson (1965), es decir, por el divisar que las acciones colectivas están mediadas por una evaluación de tipo costo / beneficios por parte de los individuos intervinientes; ha permitido arribar a posibles respuestas respecto a porque los actores sociales no participan en asuntos colectivos pero ha tenido, a la inversa, serias debilidades para explicar por qué sí lo hacen (aun cuando las pronósticos para los propios sujetos participantes les indicarían, por caso, riesgos o pérdidas materiales mayores a las que se podría obtener involucrándose en las acciones colectivas).

Desde otra tradición de pensamiento, la de autores europeos como Melucci o Touraine que reivindicaron la importancia de abordar y detenerse en aspectos como la identidad común de quienes se movilizaban, se divisó en las luchas colectivas (ligadas a las causas pacifistas, contra el racismo, la contaminación o el feminismo) como nuevas y sociales de allí el rótulo de "nuevos movimientos sociales" muy en boga en la literatura dedicada al tema en los años 1960 , '70 y ' 80 . Tal concepción no obstante fue pasible de críticas decoloniales en razón de que las causas y sus actores antes que nuevas/os tenían una largo derrotero histórico en las que fueron invisibilizadas por parte de las estructura de poder hegemónico, empero también fueron objeto de críticas por lecturas pos-fundacionales (autores como Laclau y Mouffe 1985, Laclau 2000, Ranciere 2010) que objetaron la caracterización "social" dado que con este adjetivo se opacaba el carácter político de las luchas, es decir su potencial disruptivos frente al orden social sedimentado.

En base a estas críticas consideramos oportuno remitirnos a reflexiones contemporáneas que reivindican la centralidad del conflicto, el antagonismo y lo político en tanto modo en que se instituye lo social (Mouffe, 2007) para pensar desde allí las acciones colectivas desarrolladas por diversos actores en lucha.

Primeramente nos remitimos al filósofo Federico Schuster (2005) a los fines de introducirnos en lo que a la acción colectiva, la protesta social y los movimientos sociales refieren para luego, en los siguientes apartados, poder analizar la praxis de las asambleas socioambientales en relación a las universidades en el marco de la conflictividad por el avance del agronegocio. En primer lugar podemos decir entonces que la acción colectiva constituye una categoría mucho más amplia que la de protesta y la de movimiento social; la acción colectiva es cualquier acción que requiere de la participación cooperativa de al menos dos individuos para su realización 3 . De este modo tanto la protesta social como los movimientos sociales constituirían dos ejemplos de acción colectiva dado que ambos implican la participación cooperativa de al menos dos personas. No obstante es necesario distinguir la protesta social de la noción de movimiento social, pues al decir de Schuster (2005) la idea de movimiento remite a un carácter de continuidad que la protesta no necesariamente tiene, un movimiento si es tal incluye: identidad colectiva, organización, continuidad en el tiempo, extensión en el espacio. Elementos éstos que no necesariamente deba tener toda protesta social, de hecho “(...) una protesta puede perfectamente surgir de la nada, en el sentido de no ser emergente de ningún movimiento constituido previo a ella. Y una protesta puede derivar en la nada, en la medida en que no se perpetúe en ningún movimiento que la continúe" (...) (Schuster, 2005:46).

El filósofo citado definirá a la protesta social como aquellos “(...) acontecimientos visibles de acción pública contenciosa de un colectivo, orientados al sostenimiento de una demanda (en general con referencia directa o indirecta al Estado)" (Schuster, 2005:56).

hora bien el carácter de larga temporalidad, de continuidad en el tiempo, de los que serían tributarios los movimientos sociales permite dar cuenta de una de sus características pero no agotar su definición. Por tal motivo es que consideramos clave adicionar una dimensión no explicitada en la conceptualización de Schuster para pensar los movimientos sociales y que es la referida a la alteridad. Siguiendo a Aboy Carles (2011) ${ }^{4}$ alteridad refiere al antagonismo, esto es la identificación de ese otro responsable de mis insatisfacciones e injusticias pero definitivamente constitutivo de un nosotros. Tal referencia allanará el camino para pensar qué lugar ocupó Monsanto respecto a los procesos de identificación de quienes integran 
las Asambleas y de cómo concibieron a las universidades públicas en sus disputas frente a los actores ligados al agronegocio.

En otros términos, al referirnos a la idea misma de conflictos debemos reconocer también a los actores sociales con los cuales los movimientos socioterritoriales han confrontado. Pues el conflicto supone disputas entre sujetos colectivos con el fin de alcanzar uno o más objetivos determinados a partir de intereses divergentes, en el límite, incompatibles (Ansaldi y Giordano, 2012). Corporaciones productoras y comercializadora del paquete tecnológico del agronegocio, grandes productores rurales, sectores estatales, constituyen -en un a priori no exhaustivo- los actores con los cuales las Asambleas han desarrollado antagonismos en el marco del orden hegemónico estructurado por el agronegocio.

En lo que atañe a la caracterización/compresión del agro dominante en Argentina entendemos que se trata de una lógica productiva que se caracteriza por cinco elementos: la transectorialidad; la priorización de las necesidades del consumidor global; la generalización e intensificación del papel del capital en los procesos productivos; la estandarización de las tecnologías utilizadas y la generación de tecnologías basadas en la transgénesis; y el acaparamiento de tierras para la producción en gran escala (Gras y Hernández, 2013).

El proceso de modernización tecnológica que experimentó la producción agrícola en la Argentina reconfiguró las relaciones entre el campo y la ciudad por cuanto estas últimas pasaron a tener un rol clave en la reproducción de las lógicas agrícolas basadas en el paquete tecnológico de los transgénicos. Al decir de Maldonado (et al, 2017) los espacios urbanos se tornaron esenciales para la realización de la agricultura moderna pues éstas proveen asistencia técnica, financiera, contable, venta de insumos químicos, biológicos y maquinaria y residencia de trabajadores y productores agrícolas. Elementos todos ellos claves para la reproducción de las lógicas agrícolas dominantes ${ }^{5}$.

Resulta importante advertir que la lógica del agro como negocio se expande en la Argentina desde mediados de la década de 1990 cuando el estado argentino tras desregular las juntas reguladoras de granos dispuso, a instancias de la Secretaría de Agricultura, la aprobación de la utilización de semillas transgénicas para la producción agropecuaria (el primer evento aprobado -1996- lo fue la Soja RR patentada por Monsanto). La referencia al estado nos obliga a una definición del mismo que nos permita comprender su actuación en la conformación del orden hegemónico estructurado del agronegocio en la Argentina pero, al mismo tiempo, como un dispositivo en el que también tendrían lugar múltiples actores y sectores críticos de los impactos socioambientales, económicos y políticos negativos del agro moderno. Esto no lleva a adoptar la caracterización que Samir Amin realiza sobre el estado; por cuanto éste "(...) rara vez es simplemente el Estado del capital, también es el producto del conflicto entre el capital y la sociedad" (Amin, 2005: 257). Esta definición refleja el carácter conflictivo y de correlaciones de fuerza que atraviesan todo estado sin embargo, como inmediatamente luego nos detendremos, es necesario añadir algunas reflexiones a los efectos de atender a la complejidad de la tensión capital / sociedad.

Las universidades estatales y públicas, como no podría ser de otro modo, están atravesadas por dicha tensión constitutiva, una vez más: la del capital y la propia sociedad civil. Empero las controversias sociotécnicas, es decir aquellas “(...) situaciones en las que aparece algún motivo de discordia o disenso entre actores ligados a la tecnociencia y actores sociales, o bien entre los distintos actores promotores de un cambio técnico -es decir, discrepancias entre expertos" (López Cerezo y Luján, 1997: 207 en Merlinsky, 2017: 228); no se agotan, según nuestra perspectiva, en análisis lineales (en el límite morales) que reducen las posiciones al interior de la academia ${ }^{6}$ entre quienes bregan por el capital y quienes defienden los genuinos intereses de la sociedad civil. Con ello no descartamos ni desconocemos que posicionamientos de actores de la producción científica universitaria estén directamente asociado a intereses del capital; lo que pretendemos advertir es que la mera representación de los intereses de la sociedad civil no tiene por qué significar necesariamente la adopción de criterios alejados de la voracidad del capital, máxime cuando es factible reconocer en la lógica del capital en general y del neoliberalismo en particular una gran capacidad para permear en la sociedad 
civil y desarrollar en, y sobre ella, formidables procesos de subjetivación política en clave de asimilación y reproducción de los patrones de la mercantilización.

Previo a continuar con las posibles derivas reflexivas que la noción de controversias socio técnicas habilita en relación a los casos de los que nos ocuparemos con posterioridad, hemos de contextualizar la tensión al interior del conocimiento científico y de este con lo social (en sentido amplio) rememorando que el sentido común construido alrededor del progreso científico y tecnológico pos segunda guerra mundial encontró en los movimientos contraculturales de los años 1960 (entre otros los movimientos pacifistas, ambientalista y antiracistas) una fuerte preocupación por el devenir del crecimiento armamentístico y la configuración tecnocrática del Estado. En tal contexto "la ciencia y la tecnología comenzaron a ser objeto de escrutinio público y se transformaron en sujetos de debate político" (López Cerezo, 1999:s/n). Sin esta problematización social resulta difícil imaginar la emergencia al interior de la producción del conocimiento científico de toda una rama reflexiva en torno a la relación entre la ciencia, la tecnología y la sociedad (CTS ${ }^{7}$.

Pero retomando la definición de López Cerezo y Luján (1997) sobre las controversias socio técnicas hemos de precisar la importancia del concepto aludido en la medida en que nos permite "(...) entender aquellos procesos sociales en que actores no expertos cuestionan y en algunos casos se movilizan en contra de la decisión de actores expertos que promueven nuevas instalaciones -o su reacondicionamiento-, la aplicación de normativas y/o la incorporación de tecnologías que implican riesgos de salud o ambientales" (Merlinsky, 2013:225). Parafraseando a Merlinsky el devenir de estas controversias en conflictos implican no solo el control de los bienes y recursos sino también respecto “(...) al poder de generar e imponer ciertas definiciones de la realidad" $(2013: 226)^{8}$.

Esto último nos lleva, en estas referencias conceptuales preliminares, a dos nociones fuertemente imbricadas en la configuración de la modernidad: ciencia y poder. La creencia religiosa del medioevo fue suplantada por otra fe, la de la ciencia como motor del progreso de la humanidad. Autoerigida como saber superior, la episteme desplazó los conocimientos y saberes producidos por fuera de la academia a mera doxa pasible de ser descartada. Tal operatoria se enmarca en lo que el sociólogo Juan Wahren (parafraseando a Santos, 2006 y Quijano, 2003) califica como un "epistemicidio" en donde los saberes de los sujetos subalternos son descalificados/invisibilizados frente una "monocultura del saber" que postula como universal y jerárquicamente superior a la ciencia moderna y occidental (Wahren, 2016).

Finalmente en lo que atañe al diseño de investigación el enfoque metodológico bajo el que cual se desarrolló la presente pesquisa fue de carácter cualitativo descriptivo, para el que recurrimos a diversas técnicas de recopilación de datos, tales como la observación participante sobre la labor de las Asambleas en cuestión (asistencia a reuniones y a intervenciones en el espacio público entre los años 2012-2014), entrevistas semi-estructuradas en base a muestras no probabilística de carácter intencional (derivado ello de investigaciones previas -Forlani, 2015-) a referentes y dirigentes de las asambleas, recopilación e interpretación de documentos oficiales emitidos por los colectivos sociales así como los producidos por las universidades y las publicaciones de la prensa (entre los años 2012 a 2014).

\section{ConteXtuAlización DE LOS CONFLiCtos}

La incorporación simultánea en nuestro país respecto a los países centrales del paquete tecnológico del agronegocio se inscribe en dos grandes hitos fundantes. Siguiendo a Giarraca y Teubal (2010) el primero de ellos lo fue el decreto de desregulación de 1991, el cual eliminó todas las juntas reguladoras de la actividad agropecuaria-la Junta Nacional de Granos, la Junta Nacional de Carnes, entre otras- que operaban en el país desde la década de 1930. El segundo por su parte remite a 1996, ao en que se libera al mercado agrícola argentino la semilla de la soja transgénica. Desde ese entonces: 
Argentina se transforma en uno de los principales países del tercer mundo en el que se cultivan transgénicos. Todo esto involucra un nuevo paquete tecnológico basado no sólo en la utilización de la semilla transgénica, sino también, en la siembra directa y el uso masivo del glifosato y otros agroquímicos (...). (Giarraca y Teubal, 2010: 119).

La expansión extraordinaria de la lógica del agronegocio configuró un sistema agroalimentario en el cual grandes empresas transnacionales pasaron a controlar áreas claves tales como la provisión de semillas e insumos, industrias alimenticias, distribución y comercio de la producción.

En tal contexto nacional, la mediterránea provincia de Córdoba se conferiría como modelo en lo que respecta a la incorporación acelerada del paquete agroproductivo, tal es así que la superficie destinada a la soja transgénica en la provincia paso de alrededor de un millón ochocientos mil hectáreas en 1996/97 a más de cinco millones para la campaña 2015/16 (fuente: Ministerio de Agroindustria de la Nación), a lo cual habría que añadirle la incorporación de otros cultivos genéticamente modificados como el maíz transgénico y otros fuertemente dependientes de insumos tóxicos.

Sin embargo la expansión de esta lógica hegemónica no estuvo exenta de voces críticas. Colectivos sociales, sin perjuicio de personalidades y fundaciones ${ }^{9}$, en desacuerdo con la permanente externalización de costos de la que eran víctimas se movilizaron para denunciar los impactos socioambientales inherente al modelo de los transgénicos y sus respectivos agroquímicos. Si los hitos fundantes de la adopción de las "tecnologías de punta" en el agro acontecieron al promediar la década de 1990; el hecho ${ }^{10}$ inaugural para la movilización socioambiental arraigada al territorio en perspectiva crítica de los impactos sanitarios del agro hegemónico lo constituirá la lucha de las Madres de Ituzaingó, colectivo que impulsó el primer juicio en Argentina (año 2012) por daños a la salud derivado de la exposición a tóxicos empleados en la agricultura ${ }^{11}$.

$\mathrm{Al}$ adoptar dimensión pública el conflicto que tenía a las Madres de Ituzaingó como damnificadas, fruto de una conflictividad que trascendió lo local hasta alcanzar ponderación institucional (poder judicial), mediática y ocupación del espacio público; una pluralidad de espacios asamblearios urbanos comenzaron a conformarse en distintas localidades del país y la provincia, constituyendo una de ellas la propia Asamblea Río Cuarto Sin Agrotóxicos en la ciudad de Río Cuarto (Córdoba). En palabras de algunos de los integrantes de la Asamblea al consultarles sobre la importancia del Juicio de Ituzaingó derivado de la lucha de las Madres, esto expresaban:

“(...) movilizó mucho, de hecho el reencuentro de la Asamblea nuestra fue por ese hecho particular. Me pareció que tuvo como mucha repercusión y me parece que movilizó muchas cosas (...)" (Entrevista: Geraldine 24/4/2014). En concordancia, Natalia destaca que: "El caso del juicio del barrio Ituzaingó es lo que nos encontró algunos, nos reencontramos, y otros de distintos espacios nos sumamos, eso fue como el disparador para ver qué es lo que estaba pasando en Río Cuarto (...)" (Entrevista: Natalia, 22/4/2014). Finalmente, en la entrevista Lucia va a reconocer, tras más de un año de acontecido lo de Ituzaingó, la importancia de lo desencadenado en este barrio cercano a la capital de la provincia para la constitución y el despliegue RCSA “(...) nos determina a nosotros y eso no lo tenemos que negar porque es parte de lo que somos" (Entrevista: Lucia, 26/4/2014).

\section{MÁs Agrotecnología PARA la CóRdoba de los AGRonegocios}

En el año 2012 ceos de la multinacional Monsanto, una de las trasnacionales con mayor volumen y recaudación en el mercado de las tecnologías agrícolas modernas, anuncia tras un encuentro con la jefa de Estado de la Argentina una multimillonaria inversión para la provincia de Córdoba, más específicamente en la pequea localidad cercana a la capital, la localidad de Malvinas Argentinas. La inversión, cotizada en 1500 millones de pesos, apuntaba a la construcción de una planta para procesar semillas de maíz que de haberse construido y puesta en funcionamiento constituiría la segunda planta experimental de transgénicos más grande del mundo (La Voz, 2012).

De manera simultánea la multinacional Monsanto también construía otra planta experimental de semillas, aunque de dimensiones muchos menores, dentro del ejido de la capital alterna, esto es la ciudad de Río 
Cuarto. Tanto en Malvinas Argentinas como en Río Cuarto la construcción de las respectivas obras carecían de la presentación de los informes de impacto ambiental exigidos por ley (ver Ley General de Ambiente $25675^{12}$ ), constituyendo ésta una de las principales falencias que luego será denunciada por los espacios Asamblearios de una y otra localidad. Pero en Río Cuarto la construcción del centro experimental poseía además otras graves particularidades que la propia Asamblea Rio Cuarto Sin Agrotóxicos logró revelar ante la opinión pública ${ }^{13}$. La obra estaba formalmente adjudicada (así se constataba en las presentaciones administrativas al municipio) a una empresa local (Focseed SA) comercializadora de insumos agrícolas mas no dedicada a la investigación/experimentación. Tras evidenciarse la triangulación bajo la que operaba la multinacional el conflicto tendió a agudizarse bajo distinto repertorios de acción que ${ }^{14}$ incluyeron la presentación de notas y solicitud de informes al municipio, ocupaciones del espacio público, movilizaciones y escraches. Tal conflictividad finalmente cedió tras el decreto del intendente municipal que impidió la puesta en funcionamiento de la central experimental por las falencias en el estudio de impacto ambiental presentado con posterioridad a la construcción del edificio por la multinacional y a los efectos de "preservar la armonía en la ciudad y la posibilidad de seguir conviviendo en paz y tranquilidad" (palabras del ex intendente municipal de Río Cuarto Juan Jure, en La voz, 2013).

Previo a adentrarnos en las controversias que se originaron al interior de las universidades en el marco de las conflictividades derivadas de las inversiones para la construcción y puesta en funcionamiento de los centros experimentales sin licencia social, aprovechamos para traslucir que la inversión que la multinacional del agronegocio pretendía concretar en Malvinas Argentinas, puso de manifiesto aquello que intelectuales críticos de las lógicas neoextractivistas expresaban en sus publicaciones académicas, es decir, que más allá de las diferencias partidarias e ideológicas entre las fuerzas gobernantes existía un consenso en torno a la importancia de las commodities. El caso de Malvinas Argentina resulta ilustrativo en al menos dos sentidos: en primer lugar la valoración positiva de la inversión de la multinacional atravesó los distinto órdenes/escalas de la estatalidad (nación, provincia y municipio) y, en segundo lugar, puso en evidencia que tal consenso subyacía aun con las diferencias políticas entre las fuerzas gobernantes: Frente Para la Victoria a nivel nacional (un gobierno de características posneoliberales), Unión por Córdoba en la conducción provincial (espacio peronista conservador) y el radicalismo en el gobierno municipal (partido actualmente en la alianza neoliberal -Cambiemos- que actualmente ocupa el gobierno nacional).

\section{RESISTENCIAS URBANAS FRENTE AL AGRONEgOCIO: LA DISPUTA POR LA UNIVERSIDAD}

La reconfiguración de la relación campo/ciudad -transformaciones tecnológicas del agro medianteconstituye un fenómeno clave para comprender la emergencia de conflictividades sociales en los espacios urbanos insertos en la zona de expansión del agronegocio. Que las ciudades y sus entornos agroproductivos desarrollen vínculos relacionales, funcionales y de consumo ${ }^{15}$ cada vez más mutuamente dependientes (Maldonado, Almeida y Picciani, 2017) evidencia que los límites / las fronteras entre lo urbano y lo rural tienden a desvanecerse al punto de expresar más bien continuidades geográficas (ínfimos metros separan viviendas urbanas de cultivos transgénicos), flujos sociales (una mano de obra que ya no reside en el campo sino en la ciudad), dinámicas entrelazadas de reproducción del capital (siguiendo al geógrafo David Harvey -2013- las ciudades constituyen espacios predilectos para la reproducción del capital) y, lo ya anunciado, nuevas conflictividades sociales: si hasta entonces lo rural -fundamentalmente el carácter concentrado de la propiedad de la tierra y los desalojos forzados- era cuestionado cuasi exclusivamente por movimientos campesinos residentes en las pequeas chacras agrícolas, la emergencia de asambleas socioambientales urbanas críticas de los impactos sanitarios de los transgénicos no pueden ser obviada al momento de abordar la conflictividad rural / urbano frente al agronegocio en los tiempos actuales. 
En otros términos: la configuración de "ciudades agronegocio", es decir aquellas en donde prima la función de sostén y aporte técnico a las producciones agrícolas circundantes (Elias, 2012), aun con una valoración positiva de amplios sectores de la sociedad acerca de las dinámicas agrarias modernas -construcción hegemónica mediante- no está exenta de la posibilidad de que emerjan voces contestatarias. Es que precisamente el carácter indeterminado de lo social (Laclau, 2000) es lo que habilita la posibilidad de la dislocación de aun el orden societal mas sólidamente vertebrado. Sin constituir una necesidad histórica ${ }^{16}$, sino más bien un hecho contingente trasvasado por múltiples aristas que no tendremos oportunidad aquí de desarrollar, el orden del agronegocio en las localidades referidas fue antagonizado por las iniciativas de los dos espacios asamblearios ya nombrados: RCSA y MLPLV.

Dirigiendo el análisis hacia el eje central del presente trabajo, esto es el análisis respecto a cómo la praxis de los colectivos socioambientales (RCSA y MLPLV) repercutieron en las controversias socio técnicas que se produjeron en las universidades de Río Cuarto y Córdoba al momento de tener que fijar éstas una posición frente a una de las formas de materialización de la lógica del agronegocio (una vez más: la instalación de centros experimentales de transgénicos); señalamos, primeramente, que ambos movimientos socioterritoriales identificaron en las dos universidades nacionales y públicas de la provincia espacios a disputar a los efectos de legitimar sus reivindicaciones en torno a impedir la construcción y puesta en funcionamiento de las plantas experimentales de Monsanto.

En lo que atañe a la interacción entre la Asamblea RCSA y la UNRC hemos de comenzar destacando una particularidad que hace a la dimensión constitutiva del colectivo socioambiental referido. Tempranamente integraron esta Asamblea áreas institucionales de la propia universidad como el Observatorio de conflictos socioambientales y el Centro Agroecológico dependiente de la Secretaría de Extensión de la universidad. El interés de la propia conducción universitaria de aquel entonces (año 2012) de integrar un espacio como la Asamblea RCSA evidenciaba, más que una definición política de la casa de estudios en relación al modelo del agronegocio, la existencia de una tensión al interior de la propia universidad en su conjunto respecto a diversas posturas en lo que atañe a las lógicas agrícolas hegemónicas y subalternas ${ }^{17}$.

A partir de los registros obtenidos de la asistencia a las reuniones de la Asamblea RCSA en las semanas previas a que se le solicitara al órgano colegiado máximo de gobierno de la universidad, esto es el Consejo Superior (CS) de la UNRC, a que se expida en rechazo a la instalación de la multinacional en la ciudad; pudimos registrar en las distintas alocuciones de los miembros partícipes del colectivo socioambiental que efectivamente la universidad podía constituirse en un aliado potencial en busca de legitimar el rechazo a la instalación de Monsanto que la Asamblea públicamente intentaba concretar.

Así, efectivamente en el mes de noviembre en el año 2012 se le solicitó al CS de la UNRC a que se expida en rechazo a la instalación de la multinacional en la ciudad, instancia en la que las organizaciones y ciudadanos conformantes de la Asamblea ingresaron al propio recinto de discusión. La resultante de tal acción derivó en la decisión de la universidad respecto a la conformación de una comisión ad hoc que se encargaría de estudiar lo que representaba la instalación de emprendimientos como los que pretendía llevar adelante Monsanto en la ciudad. Interesa señalar que en esta comisión además de participar miembros del Consejo Superior, docentes e investigadores de la UNRC también lo hicieron miembros de RCSA, hecho este que queda asentado en los propios considerandos de la resolución emitida por el CS sobre el asunto referido a Monsanto ${ }^{18}$.

En función de las investigaciones recopiladas por la comisión ad hoc, el CS manifestó en la resolución $322 / 12$ un rechazo contundente a la instalación de la multinacional en la ciudad ${ }^{19}$. Al tiempo que dispuso "revisar los convenios vigentes que vinculan esta Universidad Nacional con empresas multinacionales del agronegocio monopólico e instruir a la Dirección de Asuntos Jurídicos de la UNRC que analice los procedimientos conducentes a su rescisión”. (Artículo 6). Así mismo en sus artículos 8 la UNRC sugirió al Concejo Deliberante de la ciudad de Río cuarto a que convoque a una audiencia pública para que la ciudadanía pueda debatir sobre el asunto a los fines de que ésta debata y se exprese sobre lo propio. Y, finalmente, en su artículo 9 se sostuvo la necesidad de comunicar la resolución al conjunto de las autoridades 
nacionales, provinciales y municipales para que los argumentos arribados en los considerandos así como las definiciones asentadas en la resolución sean tenidos en cuenta por el conjunto de las autoridades nacionales, provinciales y municipales.

No obstante importa asentar que la decisión del CS de la UNRC no contó con el apoyo de las autoridades decanales de la Facultad de Agronomía y Veterinaria (FAyV), para ser más exactos, el decanato de dicha facultad se ausentó el día en que se votó la resolución citada. Una clara señal de discrepancia de la facultad que se traduciría según el enfoque teórico de la presente ponencia en una abierta controversia socio técnica al interior de la academia.

Con otros protagonistas pero con semejables coincidencias, en la Universidad Nacional de Córdoba será también la Facultad de Ciencias Agropecuarias la que se abstendrá en el año 2014 cuando el Consejo Superior de dicha Universidad se dispuso rechazar la Resolución Decanal (de la Facultad aludida) N 680/14, que incluía el convenio específico de cooperación entre la Facultad de Ciencias Agropecuarias y la multinacional Monsanto. Entre los argumento del rechazo por parte del CS de la UNC se asentaba que tal convenio no considera el principio de precaución establecido por la Ley General de Ambiente invocado por el HCS (Honorable Consejo Superior) en su declaración de 2012:

(...) ni la conflictividad social que desde hace varios años se ha generado nuestra provincia no aporta soluciones integrales a la complejidad del problema y compromete a nuestra comunidad educativa con las actividades que dicha empresa pretende desarrollar en Malvinas Argentinas, las que son fuertemente cuestionadas por amplios sectores de la población (fuente: Ecos Córdoba, 2014).

Sin desconocer la posición de las autoridades rectorales (el propio rector y vicerrectora se expresaron en desacuerdo con la instalación de Monsanto sin licencia social) es menester reconocer que a diferencia de lo acontecido en Río Cuarto las controversias internas en la universidad respecto a la planta experimental en construcción en Malvinas Argentinas se intensificaron y derivaron en amenazas de acciones directas por parte de los colectivos organizados (entre ellos los miembros de MLPV). Prueba de ello se refleja en los propios considerandos de la resolución decanal de la Facultad de Ciencias Agropecuarias en la que se manifiesta "Que ante la posible 'toma' de las instalaciones del Rectorado y del Honorable Consejo Superior por parte los activistas que están en contra de la Empresa MONSANTO, se creyó conveniente adoptar medidas al respecto" (Resolución decanal 970 de 2014). Medida que implicó "Dejar sin efecto la Resolución Decanal N 。 680/14 y en consecuencia el Convenio Específico de Cooperación suscripto entre la Facultad de Ciencias Agropecuarias de la Universidad Nacional de Córdoba y la Empresa Monsanto (Artículo 1, resolución 970 decanal de 2014).

Así mismo la intervención cobró especial carácter mediático cuando en el marco de las discusiones en el órgano colegiado de esta universidad en torno a la derogación del convenio entre la Facultad de Agronomía y la multinacional Monsanto los manifestantes, tras irrumpir en el debate de las autoridades universitarias, arrojaron sobre el decano de la Facultad de Agronomía un líquido que simulaba ser glifosato y, mediante el cual, buscaban evidenciar cual era la reacción de este funcionario ante un herbicida que según su perspectiva era inocuo.

***

Ahora bien lo hasta aquí descripto, esto es los modus operandi de los asamblearios para incentivar la toma de partida por parte de las universidades respecto al agronegocio, coloca de manifiesto una disputa al interior de las casas de estudio entre actores que dirimen diferencias ineludiblemente de carácter en torno al lugar que éstas deben ocupar respecto al orden social que tiene a la lógica del agro como negocio como su principal constructor. En ese marco nos preguntamos ¿en base a qué argumentos o controversias socio técnicas se construye el diferendo finalmente político librado al interior de las universidades? ¿Cómo lo político resignifica el sustrato técnico? ¿Es posible desligar la labor científica de la praxis política, vis a vis, los posicionamientos políticos de los conocimientos científicos? 
Una posible forma de abordar estos interrogantes lo es a partir de la distinción que Karin Skill y Ezequiel Grinberg (2013) proponen para comprender (bajo "tipo ideales") los dos posicionamientos encontrados al interior de la academia en relación al glifosato (herbicida de amplio espectro) ${ }^{20}$ : una mirada pragmática propia de aquellos actores que revindican el agronegocio y conciben la instalación de plantas experimentales de semillas transgénicas como una inversiones dinamizadoras garante del progreso y la modernización tecnológica; y otra lectura precautoria en cuanto divisa en la lógica del agronegocio mecanismos de acumulación por desposesión y de profundización de las dinámicas extractivas y contaminantes.

Respecto a la mirada pragmática son ilustrativas las expresiones del decano de la Facultad de Ciencias Agropecuarias (UNC), Marcelo Conrero, quien en una entrevista concedida en el marco de su participación en la 67 exposición de la Sociedad Rural de Jesús María (año 2014) expresó en relación a la instalación de Monsanto en Malvinas Argentinas:

(...) es una planta procesadora de semillas de maíz, hay 43 en todo el país y no genera ningún tipo de contaminación (...) es la posibilidad para un pueblo que tiene la mayor tasa de desocupación de la provincia”. Al tiempo que sobre el vínculo de la facultad que preside con las empresas del agronegocio sostuvo: “(...) tenemos convenios con todas las empresas de agroquímicos y semillas porque necesitamos formar nuestros ingenieros en las últimas tecnologías, mostrarlas, poder hacer jornadas, poder hacer eventos (...) queremos albergar a los productores en nuestros campos mostrándoles lo que las mismas empresas producen, lo que la misma facultad está desarrollando. (Conrero, 2014).

En contraste queda manifiesta la postura precautoria en el posicionamiento del CS de la UNRC en su resolución por cuanto afirmó que:

(...) resulta impostergable que la universidad, en conjunto con las organizaciones sociales, los distintos niveles gubernamentales y sectores económicos, inicien acciones tendientes a mitigar y revertir las consecuencias ambientales, en la salud humana, en la desocupación, la concentración de riqueza, dependencia económica y tecnológica que trae aparejado el modelo dominante del agronegocio (...). (Resolución CS UNRC: 322/12).

En ambas interpretaciones sobre la lógica hegemónica de producción agrícola es posible advertir que los debates trascienden las apreciaciones "técnicas" para condensar en posiciones antagónicas que se circunscriben al orden de lo político y que la disputa entre las posiciones encontradas dentro de las propias universidades cobraron efectivamente dimensión pública a partir de la demanda de las asambleas socioambientales movilizadas que acudieron a ellas en pos de encontrar apoyo a sus reivindicaciones frente a la instalación de Monsanto. De allí que compartimos con Merlinsky (2015) que en definitiva las controversias sociotécnicas ponen en cuestión la frontera entre lo técnico y lo social en la propia definición de los problemas. La incorporación de actores "no expertos" no simplifican en tal marco los debates o problemas sino por el contrario contribuyen a su enriquecimiento al incorporar otras aristas o dimensiones de análisis.

En síntesis: en ambas universidades las tensiones respecto al posicionamiento frente a los centros de experimentación de transgénicos que la multinacional Monsanto pretendía instalar en dos localidades de la provincia de Córdoba cobró volumen público a partir de la iniciativa de las Asambleas RCSA y MLPV en demandar a las casas de estudio a que estas cuestionen tales emprendimientos del agronegocio.

La interpelación y búsqueda de apoyo de las universidades por parte de las asambleas adquiere dimensión toda vez que el respaldo de tales instituciones permitiría a estos actores colectivos, parafraseando a Merlinsky (2015), ayudar a desestabilizar las relaciones de poder comúnmente adversas y, junto a ello, generar las condiciones para la sedimentación de nuevos significados sociales en relación a la cuestión ambiental.

En otras investigaciones (2014) caracterizábamos el modus operandi de las asambleas socioambientales a partir del reconocimiento de una doble praxis política que encuentra, en relación a la interacción con las universidades, una manifestación empírica próxima:

(...) paralelo a la movilización social, a la ocupación y visibilización mediante diversas manifestaciones, se desarrolla una labor que podríamos denominar 'administrativa' de carácter permanente, que se basa en la presentación de notas a distintos 
entes públicos como órganos municipales, universidad, etc. en las que solicitan informes, resoluciones y expedientes, sobre situaciones que los asamblearios estaban investigando (Forlani, 2015: 236).

En efecto las Asambleas llevaron adelante solicitudes formales - presentación de notas/participación en las comisiones ad hoc-al tiempo que intervenciones directas como la irrupción en las discusiones en los órganos colegiados universitarios. Así la "vía administrativa" del reclamo se redimensiona con la predisposición para la acción directa disruptiva como forma de garantizar el tratamiento de los asuntos en cuestión y su vigencia como asunto público. En relación a ello, coincidimos una vez más con Merlinsky al advertir la importancia del antagonismo y, más precisamente, el lugar que tienen los conflictos toda vez que éstos son los que "permiten la construcción e instalación de un problema en el espacio público [ya que] generan una escena y una temporalidad donde se intercambian argumentos, se vuelven visibles formas de justificación, se modifican representaciones sociales y, en definitiva, se modifican los registros de legitimidad” (Merlinsky, 2015:2).

\section{REFLEXiOnes FINALES}

Concluimos el presente trabajo recuperando algunos aspectos abordados en apartados anteriores en vistas a otorgarles la centralidad que poseen de cara al objetivo fijado, el de describir la praxis de las Asambleas RCSA y MLPLV en relación a las controversias socio técnicas que tuvieron lugar en las Universidades Públicas de Río Cuarto y Córdoba. En tal sentido una primera conclusión deriva de la doble acepción con la que, según citamos, López Cerezo y Luján (1997) conciben las controversias sociotécnicas: controversias entre "expertos" y/o entre éstos y "no expertos". Más allá de la disputa por el estatus y jerarquías de los saberes (saber científico y saber popular) lo que los casos bajo análisis evidencian es que si bien la injerencia o interpelación por parte de los movimientos sociales en relación al saber gestado en las ciencias no constituye un factor imprescindible para el advenimiento público-político de una diferencia gestada al interior de la academia, empero las acciones colectivas de estos actores (movimientos sociales) contribuyen a la publicitación y politización de ciertas discusiones o diferencias latentes por caso en las universidades públicas.

Lo que las experiencias colectivas bajo estudio reportaron, en esta línea conclusiva, es que las controversias técnicas existentes en el seno de las casas académicas (por caso las UNRC y UNC) en torno al agronegocio, adquirieron estatus de problema público a partir de la interpelación política (disruptiva) de las Asambleas RCSA y MLPLV hacia sus órganos colegiados de gobierno (Consejos Superiores de ambas universidades). Aspecto este que trasluce la trascendencia destacada parágrafos anteriores acerca de la importancia de movilización social para que la propia ciencia y tecnología sean campos de estudio por parte de la misma producción de conocimiento científico.

Por otra parte los casos reportados ilustran de manera categórica aquella proposición de Samir Amin (2005) de pensar al estado (y dentro de ellas las universidades públicas) no como únicamente reflejo de los intereses de la burguesía (en su acepción más simplista "El gobierno del Estado no es más que la junta que administra los negocios comunes de la clase burguesa" ${ }^{21}$ ) sino como resultante de la correlación de fuerzas entre el capital y la sociedad. Solo desde allí sería posible comprender la posición política finalmente adoptada por ambas universidades aun cuando las facultades de agronomía (y sus entramados con las redes del agronegocio) tienen un peso propio notablemente fuerte en ambas casas de estudio.

En cuarto lugar las conflictividades referidas y su implosión en el seno de las comunidades universitarias y sus consecuentes posicionamientos ante la ciudanía y el resto de la estatalidad evidencia que las universidades no constituyen espacios de neutralidad política, por el contrario -como toda institución social- se encuentra atravesada por las disputas territoriales que se libran entre los proyectos políticos en tensión existentes en la sociedad. De allí que la noción misma de controversias socio técnicas no deba entenderse desligada de lo político, esto es divorciada de las plataformas políticas, de las correlaciones de fuerzas y las territorialidades 
en disputa existentes en toda coyuntura histórica. Las universidades en tal sentido (por omisión o comisión) son actores que, o bien reproducen el orden social existente o, por el contrario, tienden a su transformación.

Finalmente no deseamos concluir este trabajo sin dimensionar la importancia de lo acontecido particularmente en la UNRC de cara a construir/habilitar aquello que Boaventura de Sousa Santos (2009) refiere con una sociología de las emergencias y la búsqueda de un diálogo en pie de igualdad entre los distintos saberes. La constatación a partir de las entrevistas y, en particular, la observación participante del trabajo en conjunto entre sujetos portadores de distintos conocimientos (docentes e investigadores universitarios y miembros de la Asamblea RCSA) en la conformación de la comisión ad hoc que el CS de la UNRC resolvió crear para analizar el caso Monsanto; pone de manifiesto que el diálogo de saberes es posible y que ello no implica en lo absoluto desmerecer o marginar el conocimiento científico sino, por el contrario, enriquecerlo e integrarlo en pos de una formar del conocer que dé cuenta de la complejidad de lo social al tiempo que se predisponga como una herramienta activa de emancipación.

\section{Bibliografía}

Aboy Carlés, G. y Canelo, P (2011). Presentación, dossier identidades, tradiciones y élites políticas. Papeles de Trabajo, Año 5, $N^{\circ} 8$, pp. 8-12.

Amin, S (2005). Más allá del capitalismo senil. Por un siglo XXI no norteamericano. Buenos Aires: ed. Paidós.

Berrio Puerta, A (2006). La perspectiva de los nuevos movimientos sociales en las obras de Sydney Tarrow, Alain Touraine y Alberto Melucci. Estudios Politicos, vol. 29 (julio-diciembre): 219-236.

Biocca, M (2016). Más allá de las letras de sangre y fuego. Trayectorias de desposesión en Chaco, Argentina. Revista Población y Sociedad, v. 23 № 2

Callon, M.; Lascoumes, P.; Barthe, Y (2001). Agir dans un monde incertain. Essai sur la démocratie technique. Revue française de sociologie, 2002, 43-4. París, Seuil.

Elias, D (2012). Relações campo-cidade, reestruturação urbana e regional do Brasil. XII coloquio internacional de georitica. Bogotá. Recuperado de http://www.ub.edu/geocrit/coloquio2012/actas/07-D-Elias.pdf

Forlani, N (2015). La protesta social frente al avance del agronegocio en Río Cuarto. Revista Cronía. Vol. 11. Recuperado de: http://www.hum.unrc.edu.ar/ojs/index.php/cronia/article/view/369

Gras, C. y Hernández, V (2013). El agro como negocio. Buenos Aires, Biblos.

Giarraca, N y Teubal, M (2010). Disputas por los territorios y recursos naturales: el modelo Extractivo. Revista ALASRUNa5 p. 113, Nueva Época.

Harvey, D. (2013). Ciudades rebeldes. Del derecho a la ciudad a la revolución. Ediciones Aka!, S. A Madrid, España.. Recuperado de: http://www.cronicon.net/paginas/Documentos/CIUDADES_REBELDES.pdf

Laclau, E (2000). Nuevas reflexiones sobre la revolución de nuestro tiempo. Buenos Aires: Nueva Visión.

Laclau, E y Mouffe, C (2010) [1985]. Hegemonía y estrategia socialista. Buenos Aires: Ed. Fondo de cultura Económica.

Lodeserto, A, Sáncjez, A, Borachia, M, Quiroga, My Morel, T (2010). Paradigmas en la investigación de los movimientos sociales en América Latina. Argentina, Ediciones ICALA.

López Cerezo, J. A. y Luján, J.L (1997), Ciencia y tecnología en contexto social: un viaje a través de la controversia. En Rodríguez Alcázar, J. y otros (eds.), Ciencia, tecnología y sociedad: Contribuciones para una cultura de la paz, Universidad de Granada (Instituto de la paz y los conflictos), pp. 203-22.

López Cerezo, J. (1999). Los estudios de ciencia, tecnología y sociedad. Revista Iberoamericana de Educación. Número 20 (Mayo-Agosto 1999) 217-225 pp.

Maldonado, G., Almeida, M y Picciani, A (2017). Divisäo territorial del trabalho e agronegocio: el papel de las matrópolesnacionais e a constitucao das cidades agronegocio. En Globalizacao do agronegocio e landgrabbing. Lamparina editora. 
McAdam, D, MacCarthy J y Zald, M (1999). Oportunidades, estructuras de movilización y procesos enmarcadores: hacia una perspectiva sintética y comparada de los movimientos sociales. En: McAdam, D. et.al. 1999 Movimientos sociales: perspectivas comparadas. Madrid: Ediciones Istmo.

Melucci, A (1994) Asumir un compromiso: identidad y movilización en los movimientos sociales. En: Letra Internacional. No 34, Otoño 1994. s/d.

Merlinsky, G. (2013). Cartografías del conflicto ambiental en Argentina. - 1a ed. - Ciudad Autónoma de Buenos Aires. Fundación CICCUS. Recuperado de: http://biblioteca.clacso.edu.ar/clacso/se/20140228033437/Cartografia s.pdf.

Merlinsky, G. (2015) Una sociología reflexiva para el análisis de los conflictos ambientales. Revista Debate público. Recuperado de: http://trabajosocial.sociales.uba.ar/wp-content/uploads/sites/13/2016/03/06_Merlinsky.pdf

Merlinsky, G.(2017). Cartografías del conflicto ambiental en Argentina. Notas teórico-metodológicas. Acta Sociológica. Núm. 73, Mayo-Agosto de 2017, pp. 221-246.

Mouffe, C. (2007). En torno a lo politico. Buenos aires: Fondo de Cultura Económica.

Olson, M (1965) The Logic of Collective Action: Public Goods and the Theory of Groups. Harvard University Press, $1^{\mathrm{a}}$ edición 1965.

Pérez Ledesma, M (1994). Cuando lleguen los días de la cólera. Movimientos sociales, teoría e historia. En: Letra Internacional. No 34, Otoño 1994. s/d.

Quijano, A (2003). Colonialidad del poder, eurocentrismo y América Latina. En : Lander, E. (Comp.) La colonialidad del saber: eurocentrismo y ciencias sociales. Perspectivas latinoamericanas, Buenos Aires: CLACSO.

Ranciere (2010). En los bordes de lo politico. Ediciones La cebra.

Santos, B (2006). Renovar la teoría crítica y reinventar la emancipación social. [Encuentros en Buenos Aires]. Buenos Aires, CLACSO.

Schuster, F (2005). Las protestas sociales y el estudio de la acción colectiva. En Tomar la palabra. Prometeo Libros.

Skill, K. y Grinberg. E. (2013). Controversias socio\#técnicas en torno a las fumigaciones con glifosato en Argentina. Una mirada desde la construcción social del riesgo. En Cartografías del conflicto ambiental en Argentina. Buenos Aires. Ediciones CICCUS.

Sousa Santos, B. (2009). Una epistemologías del sur. Bs As: Editorial Siglo XXI..

Svampa, M (2009). Protesta, Movimientos Sociales y Dimensiones de la acción colectiva en América Latina. Recuperado de: http://www.maristellasvampa.net/archivos/ensayo57.pdf

Svampa, M. (2012) Consenso de los commodities, giro ecoterritorial y pensamiento crítico en América Latina. En OSAL Año XIII, $\mathrm{N}^{\circ}$ 32: 15-38 noviembre, Buenos Aires: CLACSO.

Wahren, J (2016). La Naturaleza en disputa en América Latina: La encrucijada civilizatoria entre el desarrollo y el buen vivir desde una mirada decolonial. Revista de Geografía (RECIFE). vol. 33.

\section{FuENTES ELECTRÓNICAS}

Monsanto invertirá \$1.600 millones en Córdoba y se instalará en Malvinas Argentinas (17/07/2012) Diario La Voz. En Línea. Recuperado de: http://www.lavoz.com.ar/noticias/negocios/monsanto-invertira-1600-millones-cor doba-se-instalara-malvinas-argentinas

Se rechazó la instalación de Monsanto en Rio Cuarto (22/11/2013 “). En línea. Recuperado de: http://ecoscordoba.co $\mathrm{m}$. ar/se-rechazo-la-instalacion-de-monsanto-en-rio-cuarto/

\section{Documentos}

Asamblea Río Cuarto Sin Agrotóxicos (2012): La conexión local: la obra que anunció Monsanto de una Planta Experimental de Semilla en Río Cuarto la está construyendo la empresa Focseed SA al lado de Bio4. Recuperado de: http://riocuartosinagrotoxicos.blogspot.com 


\section{RESOLUCIONES Y NORMATIVAS}

Resolución Consejo Superior Universidad Nacional de Río Cuarto (2012) 332/12. Recuperado de https://www.unrc. edu.ar/

Resoluciones Decanales de la Facultad Ciencia Agropecuarias Universidad Nacional de Córdoba (2014) N 680/14 y No 970/14. Recuperadas de: https://www.unc.edu.ar/

Ley General de Ambiente 25.675. Recuperado de: http://servicios.infoleg.gob.ar/infolegInternet/anexos/75000-799 99/79980/norma.htm

\section{ENTREVISTAS:}

Geraldine, del Vivero de plantas autóctonas Wichan Ranquen, 24/04/2014.

Lucia, miembro de la Central de los Trabajadores Argentinos (CTA), 26/04/2014.

Natalia, del Observatorio de Conflictos Socioambientales de la Universidad Nacional de Río Cuarto, 22/04/ 2014.

Marcelo Conrero, decano Facultad de Ciencias Agropecuarias (UNC). Entrevista recupera de Agroverdad. 2014. Recuperado de: https://www.youtube.com/watch?v=KKR9reY9bwQ\&t=44s

\section{Notas}

1 Desacuerdos que se inscriben, a su vez, en torno a valoraciones diferenciales en lo que refiere a la expansión de la frontera agrícola bajo la dinámica del agronegocio.

2 Para profundizar respecto a sistematizaciones sobre las distintas tradiciones en el análisis de los movimientos sociales ver, entre otros, las producciones de Pérez Ledesma (1994), Svampa (2009) y Lodeserto (et al, 2010).

3 Schuster amplía: "La definición de acción colectiva sitúa como tal desde el pago de impuestos a la huelga, desde la construcción de una cooperativa barrial a una revolución, desde la organización de un acto escolar a la edificación de un movimiento social. En síntesis, cualquier acción que requiere de la participación cooperativa de al menos dos individuos para su realización" (2005:43). Dado el carácter genérico de la referencia de la acción colectiva el propio Schuster advierte la necesidad de reparar en la especificidad y distinción entre la protesta social y los movimientos sociales.

4 El desarrollo teórico de Aboy Carles es tributario de la teoría de la hegemonía de Laclau y Mouffe y se halla en diálogo también con Ranciere al momento de divisar lo político como modo, siempre conflictivo, en el que se instituye lo social.

5 Aun no constituyendo un objeto central para el presente escrito si nos interesa rescatar esta última referencia dado que la misma permitiría contextualizar los territorios en los cuales se desenvuelve la praxis de las asambleas sujetos de estudio.

6 Vale aclarar que si bien la producción de conocimiento legitimado, por caso en relación al agronegocio, no se reduce solo a las universidades, pues involucra a institutos de investigación, empresas, etc. En el presente trabajo nos limitaremos a las universidades dado el interés y la articulación que estas representaron para las asambleas que constituyen los referentes empíricos de esta investigación.

7 Los estudios de CTS adquirirán envergadura hacia los años 1970 con una impronta "crítica respecto a la tradicional imagen esencialista de la ciencia y la tecnología, y de carácter interdisciplinar (...) En general, se trata aquí de comprender la dimensión de la ciencia y la tecnología, tanto desde el punto de vista de sus antecedentes sociales como de sus consecuencias en la comunidad y en el ambiente, es decir, tanto por lo que atañe a los factores de naturaleza social, política o económica que modulan el cambio científico-tecnológico, como por lo que concierne a las repercusiones éticas, ambientales o culturales de ese cambio." (López Cerezo, 1999:s/n.).

8 Al decir de Callon, Lascoumes y Barthe (2001) mediante la emergencia de nuevos actores afectados por un determinado problema, en nuestro caso lo referido a lo socioambiental, "se produce una reconfiguración del paisaje social" (Callon, Lascoumes y Barthe, 2001 en Merlinsky 2015:8) que, nos permitimos agregar, incide en redefinición de las perspectivas, deseos y expectativas en torno a la sociedad futura y los cambios que para ello deben producirse en relación a las vigentes relaciones sociedad, ciencia y tecnología.

9 La Fundación para la defensa del Ambiente presidida por el premio nobel alternativo, el biólogo Raúl Montenegro desde hace años cuestiona los impactos negativos sobre el ambiente de la agricultura demandante de cuantiosos insumos tóxicos.

$10 \mathrm{Al}$ referirnos a "hechos" o "acontecimientos" nos referimos a aspectos aislados o emergentes casuales "ahistóricos" sino a fenómenos que son la resultante de la convergencia de distintos factores y que implican en sí mismos “(...) procesos que 
generan una nueva dinámica en el devenir político y social; nuevos lineamientos de desarrollo y contradicciones que dan lugar a un replanteo de las alternativas históricas existentes con anterioridad" (Olsson, 1979 en Argumedo, 2004:2017).

11 Se trata de un grupo de mujeres del barrio Ituzaingó anexo de la ciudad de Córdoba capital que se opuso a las fumigaciones en los campos lindantes al barrio al constatar las diversas patologías que tenían los vecinos, enfermedades posiblemente asociadas a la exposición de los agrotóxicos. Después de más de 10 años de resistencia (desde el 2001) donde las "Madres de Ituzaingó" reclamaban el cese de las fumigaciones se logró el primer juicio oral y público de la historia argentina por fumigación de agroquímicos cerca de poblaciones urbanas.

12 ARTÍCULO 11. - Toda obra o actividad que, en el territorio de la Nación, sea susceptible de degradar el ambiente, alguno de sus componentes, o afectar la calidad de vida de la población, en forma significativa, estará sujeta a un procedimiento de evaluación de impacto ambiental, previo a su ejecución.

13 Ver especialmente el documento emitido por la Asamblea RCSA del 15 de noviembre de 2012 titulado: "La conexión local: la obra que anunció Monsanto de una Planta Experimental de Semilla en Río Cuarto la está construyendo la empresa Focseed SA al lado de Bio4".

14 Conviene asentar aquí que por repertorios de acción aludimos a los instrumentos disponibles para la acción colectiva, la expresión o metodología que ésta adopta. Resulta oportuno señalar asimismo que la noción "repertorios de acción" (junto a la referencia de "estructuras de movilización” y "estructuras de oportunidades") forma parte de un prolífico corpus teórico de ascendencia norteamericana a partir del cual diversos autores (entre otros - con sus diferencias que aquí no podremos desarrollar- Mccarthy, J; Zald, M; Tilly, C; Tarrow, S, etc.) intentan dar cuenta "cómo se desencadena, cómo se desarrolla y cómo tiene éxito o fracasa la movilización social” (Berrio Puerta, 2006:224).

15 Maldonado, Almeida y Picciani (2017) recuperando a Elias y Pequeno (2007) y a Santos (1996) expresan que así como las ciudades dotan de aportes materiales necesarios e indispensables para la reproducción de las lógicas del agronegocio en tanto fenómeno global, se ven ellas mismas transformadas por la permanente demanda de insumos que el agro efectúa sobre a ciudades. En tal sentido la dinámica de las ciudades agronegocio se desplegará al calor del consumo productivo que tendrá arrastres también sobre el consumo comsuptivo (consumo familiar).

16 Bien lo ejemplifica Mercedes Biocca (2016) al constatar diversas experiencias de asimilación del agronegocio (desde el no percibirlo como un problema hasta el reconocer tal lógica productiva como un fenómeno positivo) por parte de comunidades y actores subalternos en la provincia del Chaco.

17 La propia resolución emitida por el Consejo Superior de la UNRC (322/12) en rechazo a la instalación de Monsanto en Río Cuarto evidenciaba la existencia hasta la fecha de Convenios de la propia institución universitaria con multinacionales del agronegocio. Referencia esta que traslucía la heterogeneidad de posiciones en simultáneo al interior de la propia universidad, en tanto ciertos actores cuestionaban el modelo neoextractivista mientras otros desarrollaban labores conjuntas con privados ligados a estos patrones de acumulación.

18 Que habiendo debatido en la Comisión Ad Hoc con enriquecedores intercambios de opiniones entre los integrantes de la misma y organizaciones sociales y, analizados los diferentes aportes de los campos disciplinarios que entienden en esta temática, se acuerda estar en situación de proponer al Consejo Superior consideraciones al respecto (Resolución 322/12 del año 2012, las cursivas son nuestras).

19 (...) expresar públicamente el desacuerdo de la UNRC respecto de la instalación de las empresas multinacionales del monopolio del agronegocio en particular Monsanto, en la Ciudad de Río Cuarto (...) fijando posición al respecto en relación a que las mismas representan paradigmáticamente un avance de dicho modelo de acumulación por desposesión que pudiera vulnerar la soberanía nacional y popular, con posibles consecuencias ambientales y con el agravante que no se informó debidamente a la población posiblemente afectada de los riesgos descritos, a los fines de que esta debata y se exprese sobre lo propio (Artículo 7).

20 La lógica del agronegocio no se reduce desde luego a un herbicida en particular como lo puede ser el glifosato; pero sí de su referencia, en tanto símbolo del modelo, es posible desprender conclusiones que tengan al agro como negocio como objeto analítico macro sobre el cual se dirimen diferencias respecto a la naturaleza de sus impactos (positivos y/ o negativos).

21 Engels, F. y Marx, C. (2011). Manifiesto comunista. Centro de Estudios Socialistas Carlos. México. 